\title{
SOLUTION IN A DISSOLVED SOLID
}

\section{CHARLES L. PARSONS}

It was shown in the preceding paper that when beryllium hydroxid dissolves in a solution of one of its normal salts no evidence of any molecular complex or colloidal condition could be obtained, and it was proposed as a solution of the problem that the dissolved beryllium salt acted as a solvent for the beryllium hydroxid in exactly the same manner that acetic acid dissolved in water will dissolve camphor which is itself insoluble in water. It was stated that the two cases were perfectly analogous in their physical chemical behavior, and since no assumption of complexes was necessary in the one case none was necessary in the other. It is the purpose of this paper to study in some detail ternary mixtures in which the solute is itself insoluble or but slightly soluble in that one of the mixed solvents which first separates as a solid phase on cooling. There can be no question that the study could well be made to include the whole field of ternary mixtures and that much light would be thrown upon some obscure questions by so doing, but it is without the province of the present paper or its author to enter into the broader subject.

Two facts should be stated: First, there has been for some time in the literature of chemistry a clearly defined principle, apparently unnoticed by most writers, which will explain many of the seeming discrepancies of the dissociation theory without the assumption of complex molecules. Second, a dissolved solid itself frequently acts as a solvent or, if one prefers so to view it, alters the nature of the liquid in which it dissolves, the resultant solution becoming a true solvent with an entirely different freezing-point which is raised in the particular case under consideration. It may be, however, variously affected according to the solubility relations which the three components of the ternary mixture bear to each 
other. Unfortunately the effect must, for the present at least, remain qualitative only.

The teacher of modern physical chemistry has many seeming discrepancies among the results of experiment to explain, or to pass over as unexplainable in the present condition of the science, and in no branch of his efforts is the more handicapped than in a critical study of the theory of electrolytic dissociation. The bright student, who is told that a molecule of an undissociated substance lowers the freezingpoint of water $1.86^{\circ}$ but that if the freezing-point actually found happens to be too high it is caused by the molecules forming a smaller number of complexes, while if it is too low, it is explained by partial or complete dissociation into ions, while if altogether too low for this to apply it is due to the molecules removing water from the solution to form hydrates and thus diminishing the mass of the solvent, finds himself in the same state of mind that the modern scientist views the ancient "quintessence," although that principle, since it conveniently explained everything, was sufficient for the philosophy of an Aristotle.

Anything, therefore, which serves to remove the necessity for such supposition is to be welcomed, and while the present writer by no means doubts the existence of complex molecules he believes they have many times been assumed to exist where the facts are quite the opposite and that a logical explanation without the necessity of the assumption will help rather than injure the theory of electrolytic dissociation.

In the literature we find many instances where the freezing-point has appeared abnormally high and where consequently complex molecules have been assumed; we also find ${ }^{1}$ a perfectly logical and irrefutable qualitative explanation of such facts without any such assumption, although no application is pointed out.

R. Mihaly ${ }^{2}$ finds that water exerts great influence on the freezing-point of a mixture of benzene and alcohol and that the

1 Miller: Jour. Phys. Chem., I, 634 (1897).

2 Zeit. phys. Chem., 24, I3 (I897). 
addition of successive amounts of water raises the freezingpoint continuously to the point where the whole separates as two liquid layers. The results are ascribed to the formation of the complex $9 \mathrm{C}_{2} \mathrm{H}_{5} \mathrm{OH} .3 \mathrm{H}_{2} \mathrm{O}$ which, on dilution, breaks down conveniently into $6 \mathrm{C}_{2} \mathrm{H}_{5} \mathrm{OH} .2 \mathrm{H}_{2} \mathrm{O}$ and ${ }_{3} \mathrm{C}_{2} \mathrm{H}_{5} \mathrm{OH} . \mathrm{H}_{2} \mathrm{O}$ as becomes necessary to satisfy the particular freezing point obtained. Mihaly finds similar results when water is added to a mixed solution of benzene and phenol and here the complex is supposed to be ${ }_{2} \mathrm{C}_{6} \mathrm{H}_{5} \mathrm{OH} \cdot \mathrm{H}_{2} \mathrm{O}$ which, upon dilution, dissociates into water and phenol, but even then the supposition does not fully explain the abnormal freezing point. Quite comparable results are also obtained by the addition of water to a mixture of benzene and acetic acid and also Mihaly states that when glycerine, lactic acid or other material was used which was soluble in the dissolved liquid but insoluble in benzene, perfectly analogous results were obtained and considers the result due to complex molecules.

LeBlanc and Noyes ${ }^{1}$ find that lead nitrate added to a solution of potassium nitrate does, not lower the freezingpoint so much as when added to solutions of sodium nitrate and that its solubility in water is greatly increased by the addition of potassium nitrate. It is assumed that double salts must be formed. Working with $\mathrm{HgCl}_{2}$ in aqueous hydrochloric acid like results were obtained, and it was concluded that all the $\mathrm{HgCl}_{2}$ and $\mathrm{HCl}$ is combined as the double salt, $\mathrm{HgCl}_{2} \cdot 2 \mathrm{HCl}$, which breaks up on dilution. If $\mathrm{NaCl}$ or $\mathrm{KCl}$ were substituted for the $\mathrm{HCl}$, like effects were noticed, and in each case the solubility of the $\mathrm{HgCl}_{2}$ is notably increased over that in pure water.

LeBlanc and Noyes also made a study of the effect of iodine upon a solution of potassium iodide and of silver cyanide upon a solution of potassium cyanide and in both instances found that the freezing-point was raised by the addition of the solute. In the case of potassium iodide the reason assigned was the formation of $\mathrm{KI}_{3}$ and they also con-

1 Zeit. phys. Chem. 6, 386 (1890). 
cluded that the amount of free iodine present must be very small and no greater than its solubility in pure water. With potassium cyanide the formation of $\mathrm{KAgCN}_{2}$ was not sufficient to satisfy the results and the explanation was offered that $\mathrm{AgCN}$ was added in stages to $3 \mathrm{KCN}$, forming the complexes $\mathrm{K}_{3} \mathrm{Ag}(\mathrm{CN})_{4}, \quad \mathrm{~K}_{3} \mathrm{Ag}_{2}(\mathrm{CN})_{5}$ and $\mathrm{K}_{3} \mathrm{Ag}_{3}(\mathrm{CN})_{8}$. LeBlanc and Noyes also studied the conductivity of most of the mixtures and the conductivity decreased in each case, a result in accord with the assumption of a smaller number of molecules being formed.

Waddell ${ }^{1}$ shows that salicylic acid added to a mixture of acetone and water raises the freezing-point of the solution and that the same result is obtained if phenol, paranitrophenol or hydroquinone is the solute. He makes no assumption of complexes being formed as he expected these results from a study of McIntosh's generalization" that the "addition of a substance to a binary solution in equilibrium with a solid phase raises the freezing-point if the substance added be non-miscible with the component appearing as solid phase." McIntosh studied the addition of water to a mixture of benzene and methyl alcohol, and to a mixture of benzene and ethyl alcohol and found that the freezing-point was raised in each case. He also found that the further addition of cupric chloride, which is insoluble in benzene, to these solutions caused a further rise in the freezing-point.

The whole matter has been beautifully cleared up mathematically by Miller, ${ }^{3}$ who, starting with a theorem of Gibbs, shows thermodynamically that in all such solutions as those so far cited the freezing-point must rise. According to Miller this becomes apparent since Gibbs has shown the connection between the potentials of the various components of a liquid or solid phase and their vapor tension, ${ }^{4}$ and Guldberg ${ }^{5}$ has

${ }^{1}$ Jour. Phys. Chem., 3, I60 (I899).

2 Ibid., I, 492 (1897).

s Ibid., I, 634 (I897).

4 Gibbs, p. 225.

5 Comptes rendus, 70, 1349 (1870). 
shown the relation between vapor tension and freezing-point, and. van't $\mathrm{Hoff}^{1}$ has shown the relation between vapor tension and osmotic pressure. Miller completes the chain by showing that the potential is a function of the solubility and that if a solution of a substance $S$ be prepared of equal concentration in different solvents, the potential will be greatest for that solution which is nearest saturated; or the greater the solubility in any solvent the less the potential for any given concentration. Therefore, when to a solution of $S$ in a liquid mixture of $\mathrm{A}$ and $\mathrm{B}$ there be added an additional quantity of $A$, the potential will be increased if less $S$ can dissolve in the mixture after addition of $A$ than before and vice versa. It follows from this that where the solubility of a substance in a mixed liquid consisting of two substances $A$ and $B$ is diminished by addition of the substance $A$, which separates as the solid phase on cooling, the addition of $\mathrm{A}$ will raise the potential of $S$ and its vapor tension and the temperature at which it is in equilibrium with solid A will rise also. These are exactly the conditions in every case cited above. Miller points out further the bearing upon the freezing-point, boiling-point, etc., of ternary solutions under conditions other than the particular one above cited, but the far-reaching effect upon the question of molecular complexes, dissociation and abnormal lowering is not indicated and seems to have been lost from sight by subsequent writers. This is true in the case where a dissolved solid takes the place of a second liquid, for then the number of published investigations is greatly multiplied.

Although the resemblance of a mixture of water and alcohol (or acetic acid) to a mixture of water and potassium iodide is obvious, it is certainly true that the thought of the average writer is that iodine will dissolve in the first mixture simply because it is soluble in alcohol, but the idea that it can dissolve in the second simply because it is soluble in potassium iodide seems never to have occurred to the many investigators of this interesting phenomena. It is certainly

${ }^{1}$ K. Svenska Vet. Akad. Hand1. 2I, 2 I (1 384 ). 
true that there are striking analogies in the two instances and the solubility of the iodine increases respectively with the concentration of the alcohol or the potassium iodide. It will be held by some, and perhaps correctly, that the iodine is not soluble in one component of the binary mixture but in the liquid phase considered as a single liquid. Since the difference is simply one of the melting-point of one of the components, there is no difference whatever between a dissolved solid and a dissolved liquid and we have just as good a right to consider the iodine as soluble in the potassium iodide, itself rendered liquid by its solution in water, as we have to consider it soluble in aqueous alcohol, and per se, there is no more necessity to assume the formation of complex molecules in the first case than in the second to explain a rise in the freezing-point. In both cases the results follow from Miller's ${ }^{1}$ deduction, since the saturated solutions if diluted with water precipitate iodine. The value of this point of view becomes more apparent if we consider the solubility of iodine in aqueous acetic acid. Ordinarily this is considered a case of mixed liquids, but if we happen to be working at a temperature below $16.6^{\circ}$ we are in reality dealing with a dissolved solid. Iodine raises the freezing-point of such a liquid as does camphor or any other solid which is soluble in acetic acid and insoluble or but slightly soluble in water, always providing of course we are working with such concentrations of acetic acid that it is water which first crystallizes on cooling.

The idea that there is probably little difference, if any, between a binary liquid mixture in which one component is a solid and where both components are liquid is by no means new and is discussed by Bancroft in his paper on ternary mixtures, ${ }^{2}$ and indeed this author appears to have held clearly the idea that a solid in solution might act as a solvent.

Lumsden, ${ }^{3}$ has recently given additional evidence as to

${ }^{3}$ Loc. cit.

2 Proc. Am. Acad., 30, 324, 365 (1894).

${ }^{8}$ Proc. Chem. Soc., 22, 307. 
the status of a dissolved solid by showing from values deduced from atomic volumes and atomic refractions "that a solid assumes in solution the volume which the same weight of it would have if it existed as a liquid at the same temperature."

In order to study further the matter under discussion and if possible to bring additional evidence to bear on its solution, it was decided to make a study of the freezing-point, conductivity, and dialysis of some typical ternary mixtures. In a few instances only had the conductivity of such mixtures been. studied and in those cases reported the conductivity had diminished where the freezing-point had risen, bearing out the assumption of the formation of complexes. It will be seen in the following pages that this is not always true but that quite to the contrary the conductivity may be notably increased while the assumed osmotic effect diminishes. It was thought, too, that dialysis might throw considerable light on the question, for where all three components of the ternary mixtures passed freely through parchment there would be a separation of that portion which diffused more readily, presumably the molecule of least molecular weight. On the other hand, if the solution contained complex molecules, these should pass through the parchment as such.

I desire to express my appreciation of the assistance of Messrs. J. C. Clark, C. A. Dodge and H. F. French in carrying out the main details of the experiments here described.

\section{Camphor, Acetic Acid and Water}

It is a well-known fact that camphor is fairly soluble in strong acetic acid, almost insoluble in water and that in a mixture of the two its solubility increases with the concentration of acetic acid. As it is difficult to imagine this substance forming a complex with the acetic acid and as it is a nonelectrolyte, the case seemed worthy of study.

When camphor was added to aqueous acetic-acid containing 33. I percent $\mathrm{CH}_{3} \mathrm{COOH}$ the following results were obtained. The exact mode of procedure was naturally to prepare the stronger solution first and dilute this with the 
pure solvent. The conductivities are expressed in reciprocal ohms.

Solvent, 33.I grams acetic acid in Ioo cc. solution Solute, camphor

\begin{tabular}{c|c}
\hline Grams camphor in I00 cc. solvent & Freezing-point \\
\hline 0.1098 & +0.04 \\
0.2606 & +0.09
\end{tabular}

Specific conductivity $25^{\circ}$

33 percent acetic acid ( $\mathrm{I}$ cc. contained $0.3736 \mathrm{~g} . \mathrm{CH}_{3} \mathrm{COOH}$ ) $=0.00152 \mathrm{I}$

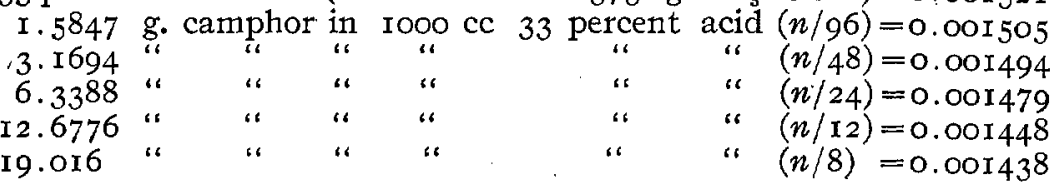

Solvent, 49.2 I grams acetic acid in Ioo cc Solute, camphor

\begin{tabular}{c|c}
\hline Grams camphor in roo cc solvent & Freezing-point \\
\hline o. I 585 & +0.125 \\
0.4489 & +0.205 \\
0.6689 & +0.475
\end{tabular}

Specific conductivity $25^{\circ}$

50 percent acetic acid ( $\mathrm{I}$ cc contained 0.5355 g. $\mathrm{CH}_{3} \mathrm{COOH}$ ) $=0.000942$ I. 5847 g. camphor in IOOO CC 50 percent acetic acid $(n / 96)=0.0009298$ 3.1694 "

6.3387

I2.6775

19.0162 "

$38.0325 “$ 76.065

\begin{tabular}{|c|c|c|}
\hline 66 & 66 & "6 \\
\hline 16 & " & a6 \\
\hline " & " & $a$ \\
\hline as & 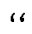 & 16 \\
\hline$\cdots$ & 16 & 6 \\
\hline 6 & " & 66 \\
\hline
\end{tabular}

16
16
6
16
16

$(n / 48)=0.0009258$

“ $(n / 24)=0.0009118$

" " $\quad(n / 12)=0.0008928$

" " " $(n / 8)=0.0008690$

" " " $(n / 4)=0.0008$ 158

In studying the dialysis of these solutions of camphor only qualitative experiments were made but they are in perfect accord with the dialysis of beryllium hydroxid in beryllium sulphate solution mentioned in the preceding paper. The camphor passed readily through the membrane 
if the outer liquid was acetic acid. It was precipitated within the membrane and very little passed through if pure water was the outer liquid, while the acetic acid passed readily. If the acetic acid was allowed to concentrate in the outer liquid, more camphor passed and would probably have continued to the saturation point of this dilute acid.

\section{Iodine, Acetic Acid, Water}

The ternary mixture was prepared in the cold as it was found that the iodine attacked either the acetic acid or the water if the solution was heated in a pressure bottle to aid solution, as had been done with the camphor. The results on the freezing-point are quite similar to those with camphor, but the specific conductivity increases instead of diminishes.

Solvent, $49.2 \mathrm{r}$ grams acetic acid in Ioo cc Solute, iodine

\begin{tabular}{c|c}
\hline Grams iodine in Ioo cc solvents & Freezing-point \\
\hline 0.2180 & +0.055 \\
0.5782 & +0.535 \\
\end{tabular}

Specific conductivity $25^{\circ}$

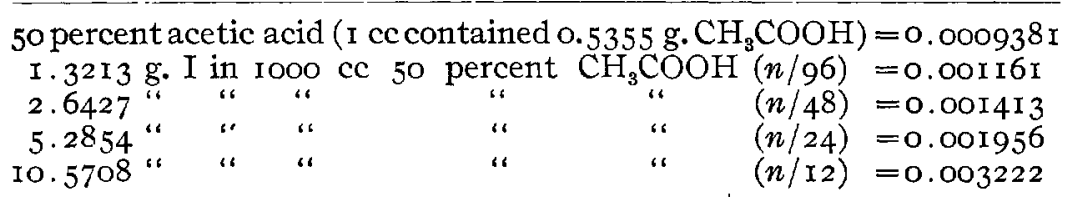

\section{Lead Oxide, Lead Acetate, Water}

The solubility of lead oxide ( $\mathrm{PbO}$ ) in lead acetate has long been known, and the resultant solution under the name of basic acetate has long been of importance for clarifying sugar solutions. The freezing-point is here again raised by the addition of the solute and we have a second instance where the conductivity increases, although not to so marked an extent. The lead oxide was made by igniting the nitrate. 
Solvent, I6.248 grams lead acetate in roo cc solution Solute, $\mathrm{PbO}$

\begin{tabular}{c|c} 
Grams PbO in Ioo cc solvent & Freezing-point \\
\hline I.33I6 & 0.09 \\
1.8996 & $0.1 \mathrm{I}$ \\
2.2160 & 0.12 \\
2.6632 & 0.139 \\
3.324 & 0.168
\end{tabular}

Specific conductivity $25^{\circ}$

3 percent lead acetate solution $=0.004048$

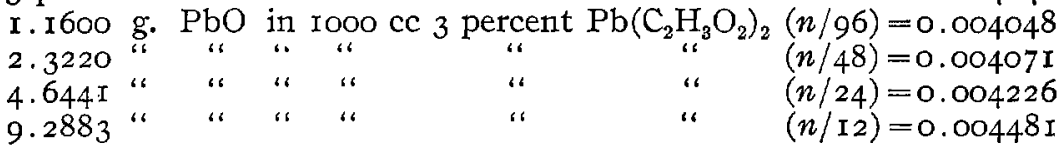

\section{Iodine, Potassium Iodide, Water}

The solution of iodine in aqueous potassium iodide presents striking analogies to many well-known facts connected with the solution of a solid in a binary liquid mixture. The solubility of the iodine increases with the concentration of the potassium iodide component, and it is precipitated in quantity from a saturated solution by addition of water. The freezingpoint of a solution of potassium iodide is raised by the addition of iodine and its conductivity is diminished as has been shown by LeBlanc and Noyes. ${ }^{1}$ Measurements made in this laboratory are entirely confirmatory of their experiments as the following tables will show.

Solvent, Io grams KI in $100 \mathrm{cc}$. solution

Solute, iodine

\begin{tabular}{c|c}
\hline Grams iodine to I0o cc KI solvent & Freezing-point \\
\hline 3.7155 & +0.017 \\
4.3348 & +0.022 \\
5.2016 & +0.040 \\
6.5022 & +0.070
\end{tabular}

1 Zeit. phys. Chem., 6, 398 (1890) 
Specific conductivity $25^{\circ}$

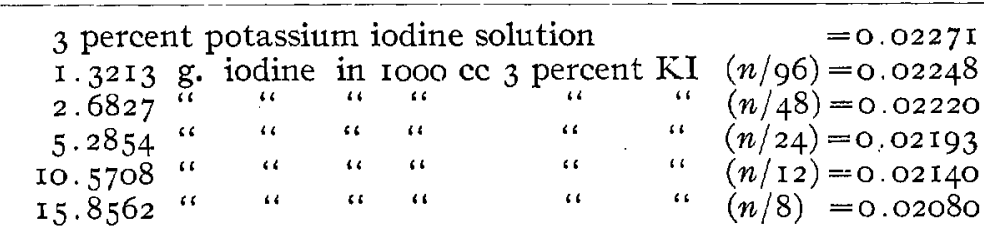

The solubility of iodine in potassium iodide solutions has been extensively investigated with widely varying conclusions. It is not within the province of this paper to go at length into the literature or the results attained, as the subject is being studied in this laboratory and will be presented later in a special communication. It may be noted, however, that the comprehensive work of Jakowkin ${ }^{1}$ is based wholly upon the distribution coefficient between iodine and water and if the iodine is also soluble in the potassium iodide, as it would be in a liquid like aqueous alcohol, his conclusions have nothing whatever to rest upon. The results of Noyes and Seidensticker ${ }^{2}$ should be expected if iodine were largely soluble in potassium iodide and slightly soluble in water and the examination was made of solutions of high dilution but still strong enough to have the solvent action of the potassium iodide of account while weak enough to have the mass of the iodine dissolved in the water effective in the equation. It should also be remembered that while the mass law equation $\mathrm{KI}_{3}=\mathrm{KI} \times \mathrm{I}_{2}$ apparently holds for these dilute solutions it certainly does not hold in the strong solutions for where saturated with iodine, the equation becomes $\mathrm{KI}_{3}=\mathrm{KI} \times$ constant, or the concentration of the $\mathrm{KI}_{3}$ is directly proportional to the KI and dilution should bring about no precipitation of iodine which really occurs in large quantity.

The fact that other investigators have obtained solid residues which analyze in the ratio $\mathrm{KI}_{3}$ is no proof whatever that this substance exists in solution; nor for that matter

${ }^{1}$ Zeit. phys. Chem., 13, 539 (1894); 20, 19 (1896).

a Jour. Am. Chem. Soc., 2I, 219 (I899). 
is the solid itself necessarily more than a solid solution or perhaps even a mixture.

The last and best word upon the subject is from Abegg and Hamburger, ${ }^{1}$ who have conclusively shown by equilibrium experiments that no polyiodide of lithium or sodium exists at $25^{\circ}$ and that if there is a polyiodide of potassium it has a complexity of at least $\mathrm{KI}_{7}$. Their melting-point clata on mixtures of potassium iodide and iodine show that iodine is certainly soluble in large amounts in potassium iodide to form a solution which is liquid as low as $82^{\circ}$. It is certainly open to question whether they obtained a maximum in their curve near this temperature indicating the presence of $\mathrm{KI}_{7}$ and the data would serve almost as well to show a flat in the curve and the probable separation into two liquid layers. Preliminary experiments made in this laboratory with mixtures of potassium. iodide and iodine in the ratio $\mathrm{KI}: 3 \mathrm{I}_{2}$ melted easily at about $82^{\circ}$. The melt was sealed off in a closed tube and thoroughly mixed by shaking while melted. It was then kept for twentytwo hours in a thermostat at $85^{\circ}$ and quickly cooled in cold water. On analysis the top portion showed a ratio as low as I.5 KI: $\mathrm{I}_{2}$ while the bottom of the mass gave I KI: $5.8 \mathrm{I}_{2}$ bitt both looked alike. While the mass was shown by analysis to be not homogeneous and was decidedly stronger in iodine in lower portions no evidence of two distinct liquid layers of definite concentration was obtained.

It is also interesting to watch the diffusion of iodine throughout a crystal of potassium iodide when the two are brought in contact although the cause therefor may be open to discussion.

Iodine and potassium iodide both pass freely through parchment when placed in contact with a liquid in which they are soluble. It was therefore reasoned that if a mixture of potassium iodide and iodine were subjected to dialysis the potassium iodide would pass much more rapidly through the membrane than the iodine if the liquid contained mixed

1 Zeit. anorg. Chem., 50, 403 (1906). 
molecules of these two substances while if the molecule was present as $\mathrm{KI}_{3}$ there was nothing in the nature of the membrane to cause it to separate into parts and the outer liquid should show the same $\mathrm{KI}: \mathrm{I}_{2}$ ratio on analysis. Numerous dialyses were tried and in every instance the potassium iodide passed through much more rapidly than the iodine as predicted. With a fairly strong solution solid iodine separated out in the inner compartment and this was the fact even in those cases where the inner solution was so dilute that iodine would not separate out on the addition of water. Unfortunately it is impossible, except with rather high concentration of potassium iodide, to reach a concentration of iodine so that the ratio $\mathrm{KI}: \mathrm{I}_{2}$ holds and in any less ratio than this the argument would at once be put forward that there were present molecules of $\mathrm{KI}_{3}$ and $\mathrm{KI}$ and that in this mixture we should expect, even more, that the KI would diffuse the more rapidly. In order to overcome this difficulty a solution was chosen of such a strength that it contained in Ioo $\mathrm{cc} 2.5$ grams of $\mathrm{KI}$ in excess of that required for the ratio $\mathrm{KI}: \mathrm{I}_{2}$ or $\mathrm{KI}_{3}$. From this solution no iodine was precipitated by dilution with 2.5 percent $\mathrm{KI}$ solution although it was precipitated by water. It was reasoned that if this solution was dialyzed into 2.5 percent $\mathrm{KI}$ as an outer solution the molecule $\mathrm{KI}_{3}$ should pass as such if present, since the excess of KI, being of the same unit concentration in both inner and outer liquids, would pass equally in either direction and would in no wise influence the results. It will be at once apparent from the following data that even with this source of error removed the KI passes much more rapidly through the membrane; solid iodine separates in quantity within, owing to the lessened concentration of the dissolving KI, and there is no evidence whatever of any complex molecule passing the membrane as such. The dialysis was carried out in a parchment tube which was placed in $200 \mathrm{cc}$ of the 2.5 percent potassium iodide solution so that the level of the two liquids was approximately the same, being a little higher, if anything, in the outer liquid and the two solutions were stirred throughout 
the experiment. At stated intervals the outer liquid was removed and replaced by a fresh portion.

Outside solution contained 5 grams KI in $200 \mathrm{cc}$ of water $=30.135 \mathrm{~m} . \mathrm{mols}$.

Inside solution contained in $25 \mathrm{cc}$.

I0.977 gms. $\mathrm{KI}=66.126 \mathrm{~m} . \mathrm{mols}$.

I6. I63 gms. I $=63.68 \mathrm{~m}: \mathrm{mols}$.

$\stackrel{\mathrm{KI}}{\mathrm{I}_{2}^{-}}=\mathrm{I} .04$.

Analyses of outer solution after dialysis

\begin{tabular}{|c|c|c|c|c|}
\hline No. of dialysis & Time in minutes & m.mols I & m1. mols KI & $\frac{K I}{I_{2}}$ \\
\hline I & I 5 & 5.67 & $\mathrm{I} 2 . \mathrm{I} 4$ & 2.14 \\
\hline 2 & I 5 & $5 \cdot 37$ & I0. 3 I & I. 92 \\
\hline 3 & 30 & 8.37 & 15.69 & I. 87 \\
\hline 4 & 30 & 5.72 & 9.95 & I. 74 \\
\hline 5 & 30 & $3 \cdot 47$ & 5.23 & I. $5 \mathrm{I}$ \\
\hline
\end{tabular}

Inside solution after dialysis

\begin{tabular}{c|c|c} 
m.mols $\mathrm{I}_{2}$ & $\mathrm{~m} . \mathrm{mols} \mathrm{KI}$ & $\frac{\mathrm{KI}}{\mathrm{I}_{2}}$ \\
\hline 6.7 & 13.6 & 2.009
\end{tabular}

besides which more than 7 grams of iodine had separated out in the crystalline condition within the tube. Of this amount 6.94 grams were collected and weighed, but a small portion could not be removed from the tube.

The total ratio of $\frac{\mathrm{KI}}{\mathrm{I}_{2}}$ was therefore less than 0.4 for the inside tube after the dialysis.

There can be no question that there was a decided separation of potassium iodide from iodine by means of the parchment, and it would scarcely seem probable that a membrane could decompose complex molecules if present while it should be remembered that an outer liquid was used which would not by itself precipitate the iodine if used as a diluent. 
The free iodine was titrated with thiosulphate. The total iodine was determined in a separate aliquot part by distilling after addition of ferric chloride and sulphuric acid, in an apparatus with all joints of ground glass. The distillate which was received in potassium iodide solution was titrated with thiosulphate.

In order to run a check analysis on a compound where there could be no doubt as to the complexity of the molecule and to test the soundness of the reasoning in regard to the use of an outside solution of the same concentration as the excess of one of the components of the possible complex a solution of 2.5 grams potassium ferrocyanide in $25 \mathrm{cc}$ of $\mathrm{I}$ percent $\mathrm{KCN}$ was dialyzed into successive portions of $200 \mathrm{cc}$ each of I percent $\mathrm{KCN}$ in exactly the same manner as described in the foregoing experiments. The results are entirely in accord with the supposition made, the potassium ferrocyanide passing readily through the membrane as $\mathrm{K}_{4} \mathrm{Fe}(\mathrm{CN})_{6}$ while the concentration of the $\mathrm{KCN}$ in both inner and outer solution remained unchanged.

\begin{tabular}{c|c|c|c|c}
$\begin{array}{c}\text { Number of } \\
\text { dialysis }\end{array}$ & $\begin{array}{c}\text { N/ro I solu- } \\
\text { tion taken } \\
\text { for 25 ce }\end{array}$ & $\begin{array}{c}\mathrm{KMnO}_{4} \text { solu- } \\
\text { tion taken for } \\
50 \mathrm{cc}\end{array}$ & $\begin{array}{c}\text { Total milli- } \\
\text { mols KCN in } \\
\text { the surround- } \\
\text { ing liquid }\end{array}$ & $\begin{array}{c}\text { Total millimols } \\
\mathrm{K}_{4} \mathrm{Fe}(\mathrm{CN})_{6} \text { in } \\
\text { the surrounding } \\
\text { liquid }\end{array}$ \\
\hline $\mathrm{I}$ & 76.0 & $\mathrm{IO} .0$ & 760 & 4.005 \\
2 & 75.0 & 9.1 & 75.0 & 3.647 \\
3 & 74.5 & 7.7 & 74.5 & 3.086 \\
4 & 74.5 & 7.1 & 74.5 & 2.845 \\
5 & 74.5 & 7.0 & 74.5 & 2.805
\end{tabular}

$74.5 \mathrm{cc} n /$ Io iodine $=25 \mathrm{cc}$ I percent $\mathrm{KCN}$ $0.07382 \mathrm{gm} \mathrm{K}_{4} \mathrm{Fe}(\mathrm{CN})_{6}=\mathrm{I}$ cc $\mathrm{KMnO}_{4}$

As shown in the table the $\mathrm{KCN}$ was titrated with iodine and the $\mathrm{K}_{4} \mathrm{Fe}(\mathrm{CN})_{8}$ with $\mathrm{KMnO}_{4}$ solution. The number of millimols of $\mathrm{KCN}$ runs slightly high in the first two dialyses owing to the effect which a large excess of $\mathrm{K}_{4} \mathrm{Fe}(\mathrm{CN})_{8}$ has on the titration as pointed out by Clennel1. ${ }^{1}$

${ }^{1}$ Chem. News, 72, 227 (I895). 


\section{Silver Cyanide, Potassium Cyanide and Water}

This. system offers a peculiarly interesting field for the application of the method of reasoning already proposed because there can be no doubt of the existence of the complex molecule $\mathrm{KAg}(\mathrm{CN})_{2}$. The complexes $\mathrm{K}_{3} \mathrm{Ag}(\mathrm{CN})_{4}, \mathrm{~K}_{3} \mathrm{Ag}{ }_{2}(\mathrm{CN})_{5}$ and $\mathrm{K}_{8} \mathrm{Ag}_{3}(\mathrm{CN})_{6}$ have also been proposed as probable by LeBlanc and Noyes ${ }^{1}$ to explain the extent to which the solution of $\mathrm{AgCN}$ in $\mathrm{KCN}$ raises the freezing-point and decreases the conductivity.

To investigate the point at issue three experiments were carried out. First a solution of the ratio $\mathrm{KAg}(\mathrm{CN})_{2}$ was dialyzed and, as the data below will show, there was no separation of $\mathrm{KCN}$ from $\mathrm{AgCN}$ by the membrane but the molecule $\mathrm{KAg}(\mathrm{CN})_{2}$ passed readily as such although no attempt was made to show the exact amount. Secondly, a solution of $\mathrm{AgCN}$ in $\mathrm{KCN}$ in the proportion to form the complex $\mathrm{K}_{\mathrm{g}} \mathrm{Ag}_{2}(\mathrm{CN})_{5}$ was made up and dialyzed into pure water and the amount of $\mathrm{KCN}$ and $\mathrm{AgCN}$ that passed was determined. Finally, the same solution as used in the second experiment was dialyzed into $\mathrm{KCN}$ solution of such concentration that it was just equal to the concentration of the excess of $\mathrm{KCN}$, over the complex molecule $\mathrm{KAg}(\mathrm{CN})_{2}$, in the inside solution. The results are entirely confirmatory. In the second experiment the $\mathrm{KCN}$ molecules passed through more rapidly than the $\mathrm{KAg}(\mathrm{CN})_{2}$ which is especially apparent when we remember that there were only half so many present and in the third experiment apparently only $\mathrm{KAg}(\mathrm{CN})_{2}$ passed at all since the passage of the $\mathrm{KCN}$ was equally rapid in both directions, while the $\mathrm{KAg}(\mathrm{CN})_{2}$ in both the second and third experiment passed in amounts which agree very closely when we consider that they were carried out at room temperature on different days. It would certainly seem that the existence of any complex other than $\mathrm{KAg}(\mathrm{CN})_{2}$ was highly improbable.

Details of the three experiments mentioned follow:

1 Zeit. phys. Chem., 6, 397 (1890). 


\section{Experiment No. 1}

50 cc of $n / 2 \mathrm{KAg}(\mathrm{CN})_{2}$ (i. e., $25 \mathrm{cc} N \mathrm{KCN}$ solution saturated with $\mathrm{AgCN}$ and diluted to 50 cc with $\mathrm{H}_{2} \mathrm{O}$ ) were put in a parchment tube, and dialyzed for ninety minutes into $3,200 \mathrm{cc}$ portions of $\mathrm{H}_{2} \mathrm{O}$, each $200 \mathrm{cc}$ being used thirty minutes.

\begin{tabular}{c|c}
\multicolumn{2}{c}{ Results } \\
$\begin{array}{c}\text { Number of } \\
\text { dialysis }\end{array}$ & $\begin{array}{c}\text { N/10 AgNo taken } \\
\text { to produce cloudi- } \\
\text { ness in outer or } \\
\text { inner solution }\end{array}$ \\
\hline I & I drop \\
3 & $\begin{array}{l}\text { I drop } \\
\text { I drop }\end{array}$
\end{tabular}

\section{Experiment No. 2}

50 cc of a solution (5O cc $N \mathrm{KCN}$ saturated with $\mathrm{AgCN}$, $25 \mathrm{cc} N \mathrm{KCN}$ added and the whole made up to roo cc) were placed in a dialyzing membrane and dialyzed for ninety minutes into $3,200 \mathrm{cc}$ portions of $\mathrm{H}_{2} \mathrm{O}$, each $200 \mathrm{cc}$ being used thirty minutes. Each $200 \mathrm{cc}$ portion then made up to $250 \mathrm{cc}$ with $\mathrm{H}_{2} \mathrm{O}$ and $50 \mathrm{cc}$ taken from each $250 \mathrm{cc}$ and analyzed.

Results

\begin{tabular}{|c|c|c|c|c|}
\hline $\begin{array}{l}\text { Number of } \\
\text { dialysis }\end{array}$ & $\begin{array}{l}\mathrm{N} / \mathrm{ro}_{\mathrm{AgNO}} \\
\text { taken to pro- } \\
\text { duce cloudi- } \\
\text { ness in } \\
50 \mathrm{cc}\end{array}$ & $\begin{array}{l}\text { Wt. of AgCN } \\
\text { present in } \\
\text { 5o cc }\end{array}$ & $\begin{array}{l}\text { Total milli- } \\
\text { mols KCN } \\
\text { which passed } \\
\text { through the } \\
\text { membrane }\end{array}$ & $\begin{array}{c}\text { Total milli- } \\
\text { mols KAg(CN })_{2} \\
\text { which passed } \\
\text { through the } \\
\text { membrane }\end{array}$ \\
\hline$I$ & 2.4 & 0.0928 & 2.4 & 2.27 \\
\hline 2 & I. 8 & 0.0772 & I. 8 & I. 98 \\
\hline 3 & I. 5 & $0.06 \mathrm{I} 8$ & I. 5 & I $\cdot 56$ \\
\hline
\end{tabular}

Experiment No. 3

50 cc of a solution (50 cc $N \mathrm{KCN}$ saturated with $\mathrm{AgCN}$, $25 \mathrm{cc} N \mathrm{KCN}$ added, and the whole made up to Ioo cc with $\mathrm{H}_{2} \mathrm{O}$ ) were placed in a dialyzing membrane and dialyzed for ninety minutes into $3,200 \mathrm{cc}$ portions of $\mathrm{N} / 4 \mathrm{KCN}$, each $200 \mathrm{cc}$ being run thirty minutes. $50 \mathrm{cc}$ of each 200 were then 
taken and analyzed. $50 \mathrm{cc} n / 4 \mathrm{KCN}$ required $6 \mathrm{I} .5 \mathrm{cc} n /$ ro $\mathrm{AgNO}_{3}$.

Results

\begin{tabular}{c|c|c|c|c}
\hline $\begin{array}{c}\text { Number of } \\
\text { dialysis }\end{array}$ & $\begin{array}{c}\text { N/10 AgNO } \\
\text { taken to pro- } \\
\text { duce cloudi- } \\
\text { ness in } \\
50 \mathrm{cc}\end{array}$ & $\begin{array}{c}\text { Wt. of AgCN } \\
\text { present in } \\
50 \mathrm{cc}\end{array}$ & $\begin{array}{c}\text { Total milli- } \\
\text { mols KCN } \\
\text { which passed } \\
\text { through the } \\
\text { membrane }\end{array}$ & $\begin{array}{c}\text { Total milli- } \\
\text { mols KAg(CN) } \\
\text { which passed } \\
\text { through the } \\
\text { membrane }\end{array}$ \\
\hline $\mathrm{I}$ & $6 \mathrm{I} .0$ & 0.8924 & none & 2.39 \\
2 & $6 \mathrm{I} . \mathrm{I}$ & 0.8843 & none & $\mathrm{I} .96$ \\
3 & $6 \mathrm{I} .2$ & $0.88 \mathrm{II}$ & none & $\mathrm{I} .82$
\end{tabular}

\section{Borax, Boric Acid, Water}

Boric acid has long been known to be more soluble in a solution of borax than in pure water, and polyborates have been assumed as necessary to explain the abnormal conductivity and freezing point lowering.

Kahlenberg and Schreiner ${ }^{1}$ determined the freezing point lowering and the conductivity of boric acid and various mixtures of boric acid and sodium hydroxide. They showed that when boric acid was alone present in water the freezing point was in close theoretical agreement for the slightly dissociated acid. On the other hand, when the various sodium borates were experimented with, the results had to be explained by various assumptions depending upon the ratio between the constituents and their concentration. The most striking points brought out were that when sodium hydroxide and boric acid were mixed in the proportions $2 \mathrm{NaOH}+4 \mathrm{H}_{3} \mathrm{BO}_{3}$ the solution was identical with one obtained by dissolving an equivalent amount of borax; that if boric acid was added to either solution a relatively high freezing point was obtained which could be explained only by the assumption of polyborates, and that no single polyborate would explain the results. The rise in the conductivity was also shown to accord with this hypothesis.

The question of the presence of polyborates was also studied by Auerbach,' and later in a very exhatistive manner by Mueller

${ }^{1}$ Zeit. phys. Clem., 20, 547 (1896).

2 Zeit. anorg. Chem., 37, 353 (I903). 
and Abegg." Their conclusions were much the same and were to the effect that polyborates did exist in solution but that the conditions pointed to several complexes present at the same time. Mueller and Abegg studied especially the distribution coefficient of boric acid between amyl alcohol and water, and between amyl alcohol and water containing borax in solution, and they found from the free boric acid present no constant which would hold for either a di- tri-, tetra-, or pentaborate and concluded that several complexes must be present in equilibrium. For the purpose of the argument put forth in this paper, however, it should be remembered that their distribution coefficient depended upon the solubility of boric acid in water. If it is soluble in dissolved borate the same as if another liquid so!vent were present, it of course leads to false conclusions as to the relative distribution of the boric acid.

The question seemed one particularly susceptible to the method of treatment already put forth, as all of the constituents pass readily through a membrane and the well-known methods of titration with the addition of glycerine made the details of analysis comparatively easy. If complex borates were formed they would either fail to pass through the membrane or would diffuse more slowly than the lighter and more rapid moving molecules. In either case the outer solution would become relatively poor in the boric acid content obtained by titration. On the other hand, if complexes were not formed the boric acid would naturally diffuse more rapidly than the borax, and the amount of that component in the outer solution would increase. It will be perfectly apparent from the experiments that the last supposition is what really takes place.

Solntions representing the following ratios were made up by dissolving boric acid in sodium hydroxide solution free from carbonate and were shown to be correctly prepared by titrating each solution.

$$
\begin{aligned}
& 2 \mathrm{NaOH}+4 \mathrm{H}_{3} \mathrm{BO}_{3}\left(\text { or } \mathrm{Na}_{2} \mathrm{~B}_{4} \mathrm{O}_{7}\right) . \\
& 2 \mathrm{NaOH}+6 \mathrm{H}_{3} \mathrm{BO}_{3}\left(\text { or } \mathrm{Na}_{2} \mathrm{~B}_{4} \mathrm{O}_{7}+2 \mathrm{H}_{3} \mathrm{BO}_{3}\right) . \\
& \left.2 \mathrm{NaOH}+8 \mathrm{H}_{3} \mathrm{BO}_{3} \text { (or } \mathrm{Na}_{2} \mathrm{~B}_{4} \mathrm{O}_{7}+4 \mathrm{H}_{3} \mathrm{BO}_{3}\right) . \\
& 2 \mathrm{NaOH}+\mathrm{IOH}_{3} \mathrm{BO}_{3}\left(\text { or } \mathrm{Na}_{4} \mathrm{~B}_{4} \mathrm{O}_{7}+6 \mathrm{H}_{3} \mathrm{BO}_{3}\right) .
\end{aligned}
$$

1 Zeit. phys. Chem., 57, 513 (I g06). 
Each solution contained the equivalents of I mol of sodium hydroxide in 5 liters.

Fifty cc of each solution was placed in a parchment tube and dialyzed for four successive periods of thirty minutes each into $200 \mathrm{cc}$ of pure water at room temperature, both inner and outer solutions being stirred and the outer solution being replaced by pure water at the end of each period. The following results were obtained:

TABLE I

Inner solution, I mol NaOH and 2 mols $\mathrm{H}_{3} \mathrm{BO}_{3}$ in 5 liters $\mathrm{NaOH}: \mathrm{H}_{8} \mathrm{BO}_{3}:: \mathrm{I}: 2$

Outer solutions after dialysis

\begin{tabular}{c|c|c|c}
\hline Time, minutes & cc N/5 HCl & cc N/5 NaOH & $\frac{\text { mols } \mathrm{H}_{3} \mathrm{BO}_{3}}{\operatorname{mols~} \mathrm{NaOH}}$ \\
\hline 30 & 8.0 & $\mathrm{I} 6.5$ & 2.06 \\
30 & 7.2 & $\mathrm{I} 5.2$ & $2 . \mathrm{I}$ \\
30 & 5.8 & $\mathrm{I} 2.5$ & $2 . \mathrm{I} 3$ \\
30 & 4.9 & $\mathrm{II} .2$ & 2.27
\end{tabular}

The solute dialyzed apparently as borax, although there may be a slight tendency for the boric acid to go through the more rapidly. The difference of one-tenth in the ratio is, however, of light significance as the error is well within the limits of probability, considering the small amount of reagents used in titrating.

TABLE II

Inner solution, I mol $\mathrm{NaOH}$ and 3 mols $\mathrm{H}_{3} \mathrm{BO}_{3}$ in 5 liters

$\mathrm{NaOH}: \mathrm{H}_{3} \mathrm{BO}_{3}:::$ : $: 3$

Outside solutions after dialysis

\begin{tabular}{c|c|c|c}
\hline Time, minutes & cc N/5 $\mathrm{HCl}$ & $\mathrm{cc} \mathrm{N} / 5 \mathrm{NaOH}$ & $\frac{\text { mols } \mathrm{H}_{3} \mathrm{BO}_{3}}{\operatorname{mols~} \mathrm{NaOH}}$ \\
\hline 30 & 6.6 & 27.4 & 4.12 \\
30 & 6.9 & 24.0 & 3.46 \\
30 & 5.8 & 20.0 & 3.40 \\
30 & 5.2 & 17.0 & 3.28
\end{tabular}


It is evident that the boric acid separates by diffusion which would not be expected if it were part of a complex molecule.

TABLE III

Inner solution, I mol NaOH and 4 mols $\mathrm{H}_{3} \mathrm{BO}_{3}$ in 5 liters

$\mathrm{NaOH}: \mathrm{H}_{8} \mathrm{BO}_{3}:: \mathbf{I}: 4$

Outside solution after dialysis

\begin{tabular}{c|c|c|c} 
Time, minutes & cc N/5 $\mathrm{HCl}$ & $\mathrm{cc} \mathrm{N} / 5 \mathrm{NaOH}$ & $\frac{\mathrm{mols}_{3} \mathrm{BO}_{3}}{\mathrm{mols} \mathrm{NaOH}}$ \\
\hline 30 & 8.5 & $42 . \mathrm{I}$ & 4.93 \\
30 & 5.8 & 28.5 & 4.86 \\
30 & 5.3 & 25.0 & 4.70 \\
30 & 4.9 & 22.4 & 4.54
\end{tabular}

The ratio of boric acid is again increased by diffusion.

TABLE IV

Inside solution, I mol $\mathrm{NaOH}$ and 5 mols $\mathrm{H}_{3} \mathrm{BO}_{3}$ in 5 liters

$\mathrm{NaOH}: \mathrm{H}_{3} \mathrm{BO}_{3}::$ I $: 5$

Outside solution after dialysis

\begin{tabular}{c|c|c|c}
\hline Time, minutes & cc N/5 HCl & $\operatorname{cc~N} / 5 \mathrm{NaOH}$ & $\frac{\mathrm{mols}_{3} \mathrm{BO}_{3}}{\mathrm{mols} \mathrm{NaOH}}$ \\
\hline 30 & 5.6 & 37.6 & $6.7 \mathrm{I}$ \\
30 & 5.2 & 32.8 & 6.30 \\
30 & 5.0 & $3 \mathrm{I} .4$ & $6.2 \mathrm{I}$ \\
30 & 4.2 & 24.0 & 5.62
\end{tabular}

Again the boric acid ratio notably increased.

The results of these four sets of experiments are perfectly in accord with the supposition that the boric acid is simply more soluble in borax solution than in water and that it is mixed with borax rather than combined with it as a polyborate. It is not claimed that polyborates may not exist as solids but simply that when in solution they are not present as complex molecules nor is there any more need to assume them to be so than in the case of the alums where the freezing point is known to be in accord with simple rather than double molecules. 


\section{Summary}

It is argued in this paper that a solid in solution may, and frequently does, act toward other solutes exactly as if it was a liquid miscible in the solvent in which the second solute was itself soluble.

It is shown that if this is the case many so-called abnormal osmotic effects are readily explained qualitatively without any other assumption than that of simple solution.

It is experimentally shown in many such instances, where complex molecules have been assumed, that the two solutes tend to separate from each other by diffusion through a membrane, permeable to either, while in other cases of $\mu \mathrm{n}$ doubtedly complex molecules no such tendency exists and that the freezing-point and conductivity do sometimes, in the first instance, lead to opposite conclusions.

New Hampshire College, June, 1907. 